\title{
De onde vem tanta vagina? Xibunguismo e perversão na poesia vaginal de Glauco Mattoso
}

\author{
Mario Cesar Newman de Queiroz*
}

Este ensaio, mais do que artigo, não fará o percurso elegantemente acadêmico de apresentar o poeta, contextualizá-lo antecipada e docemente para o leitor. Para isso, nas "Referências", remeteremos diretamente o leitor a sites que tratam do autor. Trataremos de uma questão que nos surge com a publicação do livro Poesia vaginal, por Glauco Mattoso, autoproclamado podólatra. Assim, este artigo busca um golpe a fegatello. Apresentada a questão, vem a busca de uma resposta. Os dados contextuais sobre o autor serão levantados na medida da necessidade na apresentação e tratamento da questão. Ao assim proceder, busca-se abreviar o artigo e poupar o leitor do que muitos outros já possam ter feito melhor com mais espaço.

Conforme fica bem destacado na excelente entrevista que Caio Cagliardi e Pedro Marques realizaram com o poeta, no site academia.edu, o próprio poeta diz que sua postura temática é bastante anticonvencional: xibunguista, como ele diz. Xibungo, no Nordeste, é o homossexual masculino "passivo". A palavra sempre aponta para um sentido pejorativo, o xibungo é um porcaria, um desqualificável. Nessa estética assumidamente xibunguista, esse pejorativo se mantém e se revira como numa fita de Moebius. Assim diz o poeta na entrevista constante nas referências:

\footnotetext{
* Professor associado no Departamento de Letras e Comunicação da Universidade Federal Rural do Rio de Janeiro (UFRRJ).
} 
Se considerarmos a estratégia xibunguista como um mecanismo de transgressão ética e estética, bem como o fetichismo andropodólatra nos sonetos mais explícitos, a resposta é sim. Alguns acadêmicos nos States e na Europa estão analisando minha obra à luz das teorias mais recentes, como a da sensibilidade "queer", e concluem que já nem se trata, no meu caso, duma reafirmação da identidade gay como questionamento da heterossexualidade, mas sim duma proposta alternativa (portanto mais que pós-moderna) que desvia o foco das territorialidades erógenas (falocentrismo, penetracionismo, analidade etc.) e aponta para uma diversidade mais "neutra" ou degenérica - afinal, o pé em si não tem sexo...

Portanto, qual o lugar que a vagina, objeto do desejo por excelência, pode ter como tema nessa estética xibunguista? Conforme o próprio poeta afirma, sua estética é mais deslocadora do desejo para fora do registro sexual genital do que vinculável a um grupamento sexual gay, daí o canto à podologia, "porque pés não têm sexo". Então, como vieram esses 100 "sonetos sacanas" exatamente a essa Dona do registro genital, à vagina?

\section{Poesia vaginal, um pornologos?}

Poesia vaginal é publicado em 2015, com o subtítulo "cem sonnetos sacanas". Nem o título, nem o subtítulo enganam. Todos os poemas têm, diretamente ou de algum modo vagina no seu corpo, todos são sonetos, são cem e todos são sacanas.

A partir da vagina como base, primeiro ponto temático a observar será a da transgressão. A vagina aqui não se insere num 
universo lírico de enaltecimento ao feminino, como seria esperável num universo erótico da lírica luso-brasileira. Ela não aparece revestida de elevada espiritualidade. Discutível, no entanto, a nosso ver é se são poemas pornográficos, pois não se fazem na obscenidade do desnecessário apelativo. Esses poemas se enquadram naquela categoria que Gilles Deleuze situou as obras de Sade e Sacher-Masoch, pornologia (Deleuze: 1973, 17), mas por outros modos?

Deleuze retoma Sade, na verdade, ao distinguir o pornologista do pornográfico. Sade opõe o sangue frio do pornologista ao entusiasmo do pornógrafo. Ao acompanhar a leitura de Deleuze, pode-se dizer que o pornográfico, a descrição pornográfica em Sade se faz necessária pois tem na descrição um seu modo. Diversamente, em Masoch a descrição pornográfica é dispensável, pois "não as comporta essencialmente" (Deleuze: 1973, 25). Mas, tanto em Sade como em Masoch, o pornográfico não se basta em si, um logos atravessa essas descrições, essas cenas detalhadas. Esse logos faz da matéria dos corpos uma nova causa dos corpos, por isso, antes da psicanálise, não se bastam no prazer e disjungem este do gozo. Capturar algo desse logos glaucânico é o que se busca aqui: que é esse discurso vaginal?

\section{Vagina e falo, falo da vagina}

Os poemas de Poesia vaginal, longe de apontarem para um canto lírico ao amor heterossexual ou tão somente às práticas sexuais genitais, estão mais afinados à formulação lacaniana de que "não há relação sexual”. Há sexualidade, não sexo, porque não há ato sexual. Todo ato é significante e, no caso do ato sexual, o que se tem é a falta do significante. "A inexistência do ato sexual é o que Lacan define como o sentido lógico (entenda-se como sendo o sentido o cume 
do sem-sentido, do nonsense) da castração" (Rabinovich: 1996, 77; tradução nossa).

Essa formulação lacaniana retoma o nascimento da psicanálise, do discurso das histéricas a que ninguém dava ouvido. Elas diziam que nenhum homem as satisfazia. A histérica não sabe viver, pois busca "gozar" um gozo que as satisfaça e culpa o outro por isso não se dar. Freud deu atenção a essa fala, viu a verdade que está ali repetidamente dita: que a relação sexual entre homem e mulher não combina, nunca combinou e nunca combinará. Porque nascemos bicho, mas somos humanos por essa incompletude fundadora que nos faz ser um bicho incompleto, falante-ser da falta. "Coitada da Dolô! Quem dera fosse / dotada duma mansa passarinha! / Mas não! É uma nymphomana precoce!" (Mattoso: 2015, 31).

Por mais que tenhamos atividade sexual, não há propriamente relação, pois não há complementaridade entre os sexos humanos. Nunca amamos completamente o que desejamos e entre amor e desejo só conseguiremos possíveis acertos. "Boceta existe só para aguçar / a fome dos caralhos em jejum. / Queremos bedelhar, fuçar, buçar!" (Mattoso: 2015, 29). Para dar conta disso, Lacan insiste na separação de três termos: necessidade, demanda e desejo. A necessidade é suprível com direta pureza. Quem tem fome come; quem tem sono dorme; quem tem sede bebe água. Mas na cultura ocorre uma formulação da necessidade em demanda. Nunca isso se dá de forma pura, uma vez que a carne que mata a fome será cozida, preparada, temperada, comida com garfo e faca. Essa formulação da necessidade denomina-se demanda e ela introduz a ordem simbólica, simultaneamente transformando a necessidade em algo opaco, impreciso. Com a sofisticação da cultura, cada vez mais necessidade e demanda se distanciam. Nessa brecha corre o desejo. O desejo se faz ali onde a demanda produz sobre a necessidade. 
Dessa produção uma reversão se dá, não importa mais tanto o objeto dado, mas quem o dá. Dirá assim Gerard Miller: "No horizonte de toda demanda, há o amor, o ser daquele que dá, e que não pode cercar senão como alguma coisa diferente de tudo que é dado, senão como uma falta" $(1989,61)$. Assim, no poema "Sonneto sobre uma paixão cega [2933]".

Só louco pode amar desta maneira, querendo bem e, ao mesmo tempo, sendo escravo, mergulhado neste horrendo inferno tenebroso da cegueira!

Paixão tão masochista, é certo, beira a própria insanidade! Estou vivendo aos pés duma mulher! Não me defendo dum golpe, com o salto ou a biqueira...

Até que uma attitude tem, materna, minha dominadora, raramente, mas, quasi sempre, apenas me governa...

Pisando-me no rosto, está contente. Meu corpo é mero appoio à sua perna. Eu sinto amor: prazer é o que ella sente.

(Mattoso: 2015, 111)

O desejo desloca para o singular, para o único, um objeto que passa a não ter comparação com nada mais. Algo que não se pode trocar, nem comprar. Esse objeto diferenciado de todo o restante do 
mundo é denominado por Lacan de "pequeno a", surge dessa certeza de que algo nos ameaça com sua falta. Como um falo a ser perdido por uma castração sempre iminente.

O menino que descobre que nem todos têm pênis e se dá conta de que quem não tem pênis é castrada: as mulheres são castradas, nelas falta. É com essa dificuldade de lidar com a possibilidade de castração que se funda o complexo de castração. $\mathrm{O}$ falo se faz como significante de toda falta, ele nunca assegurará nenhuma completude. O falo não é o pênis, não é um órgão, é "significante do desejo", um substitutivo que está por toda falta. "O falo permanecendo o emblema de toda perda, o princípio da disjunção que distribui no mundo nossos objetos estimados" (Miller: 1989, 62).

Homem e mulher são marcados pela castração. Para o menino, a castração surge com a constatação de que existe aquela castrada, o temor da castração é real e ele se marca igual aos demais ("o homem é sempre o mesmo", "todo homem é igual"), excetua-se a mulher, esse outro que define o dentro de ser homem. No homem, há um limite que faz uma borda, um desenho onde se circunscrever. Não castrável porque já castrada a mulher não existe, ela precisa sempre se comparar com outras e se reafirmar. Ela é outra com relação ao homem e outra com relação às outras mulheres. "A" mulher não existe, mas "as" mulheres não cessam de existir, sempre mais uma, e mais uma, e mais uma... sem jamais fechar a borda que as circunscrevam. Daí esses poemas vaginais serem de matéria tão diversa, pois se a vagina é uma determinação biológica, o vaginal de que tratam os poemas de Glauco Mattoso são algo mais. Matéria de prazer, matéria de gozo? 


\section{$O$ gozo enfim?}

Joel Birman lembra que, em Três ensaios sobre a teoria da sexualidade, Freud esboçou sua primeira teoria das pulsões e mergulhou na questão da sexualidade. Com esses pensamentos e formulações, Freud desconstruía as concepções de sexo e psiquê oriundas das ciências do século XIX e as movia do plano orgânico para o plano mental. Ali ele se dava conta de que "a sexualidade seria essencialmente perverso-polimorfa", formada por entrechoques de pulsões anárquicas e parciais que buscavam o prazer e o gozo (Birman: 2014, 273-4).

"Eu, ouvindo o que ella conta, / no logar me vejo, prompta / minha bocca à dura lida..." (Mattoso: 2015, 185). Se a relação sexual não encaixa, o falante-ser é sempre solitário em seu ato sexual, em seu prazer, pois nem mesmo o prazer se encaixa no gozo. Os poemas de Poesia vaginal são cheios de perversões, transgressões, baixarias, coprofilia, sodomia, podologia, estupros, violências, personagens sádicos, masoquistas, cegos, aleijados, dominatrix, prostituição, pedofilias realizadas ou tentadas, masoquista fantasiado de bebê, masturbações, zoofilias... É preciso repetir, nos cem sonetos de Poesia vaginal, nem todos eles tratam diretamente da vagina, mas de algo mais amplo, que é o vaginal.

E como Glauco Mattoso constrói esse vaginal? Ele é construído como espaço de transgressão, de perversão, que é o resultado da distinção psíquica da sexualidade entre homem e mulher, da "castração" e do ilimitado da castrada que com a castração advém. Com isso, Glauco Mattoso escava como nenhum outro poeta brasileiro o espaço da transgressão, da perversão. Rompendo com qualquer fronteira de discurso politicamente correto, o discurso pornológico de Glauco Mattoso atua em prol de uma política de corpos muito mais livres: entre outras coisas, 
ela busca também identificar no heteronormativo o espaço "naturalizado" da perversão.

Para Freud, há dois princípios de funcionamento psíquico. Inicialmente, somente o prazer move o sujeito. O aparelho psíquico é movido pela busca de prazer e pela evitação do desagradável. Essa é uma ideia constante que percorre toda a obra de Freud (Laplanche \& Pontalis: 1992, 364-5). Mas onde está esse princípio quando o masoquista xibunguista ou uma mulher busca a dor ou a humilhação? Pergunte-se ao soneto "Fedido por fedido [3185]", que finda assim numa evocação à porcaria e a quem a encare:

Calhou de achar mulher que fosse escrava A poncto de aceitar seja o que for $\mathrm{Na}$ bocca... E ele inda manda o asseio à fava!

"Mas si ella achou que sujo é que eu lhe calho! P'ra que lavar? Ahi que eu me emporcalho!"

(Mattoso: 2015, 121)

Depois, Freud identifica um segundo princípio, o princípio de realidade, que será o responsável pela identificação no aparelho psíquico do que é a realidade, por mais desagradável que ela seja. Esse princípio suplanta o princípio do prazer e ensina o sujeito a se adaptar para sobreviver. No entanto, o princípio do prazer está lá, o princípio de realidade o supera, mas não o contradiz, o sujeito sempre estará na busca do prazer. Diante das dificuldades percebidas pelo princípio de realidade, a sexualidade se estrutura e entra em latência. A sexualidade excluída do princípio de realidade continua a buscar ser regida pelo princípio de prazer. Mas essa solução não é 
tranquila, pois ela mesma é abalada por aquela incompletude, por aquela falta fundadora, pelo não-encaixe. $\mathrm{O}$ inconsciente não se comanda pelo princípio de prazer que fica recalcado pelo princípio de realidade. E sim pelo de sofrimento.

Dessa forma, a busca pelo prazer é ainda uma busca consciente, mas a busca inconsciente é pelo gozo e ele não está afastado do desprazer, da dor. Daí a formulação da psicanálise: "você não sabe onde você goza". Solal Rabinovitch observa que "os pensamentos só são conscientes porque utilizam palavras; são necessárias palavras para saber o que se pensa" (2001, 78). O gozo não se insere no registro do consciente. Daí Lacan afirmar que "o gozo é o momento que não posso dizer" (apud Miller: 1989, 66). Pode-se dizer do prazer, do que nos traz prazer, não do que nos faz gozar. O soneto "Um magote de camarote [4027]" deixa entrever essa dificuldade entre o gozo e a consciência, o inconsciente e a palavra:

Demora no banheiro. Ou caga, ou toca

Punheta. A mãe advisa: "A virgem tá

Te vendo, hem? E Jesus, hem? Olha lá!"

Pellado, elle se encolhe em sua toca.

Demora mais um pouco. A mãe provoca:

“Cuidado, hem? Satanaz tá vendo!” Dá

Nos nervos e elle quasi que diz "Va

Tomar no cu!" Mas cala-se, o boboca.

Depois elle matuta: "Porra, é todo um bando me assistindo? Que platéa! Eu quero ter sossego e só me fodo!" 


\section{"Estavam, junctos, tendo a mesma idéa? \\ A virgem e Satan? É porra a rodo! \\ Quem sabe se é mamãe a mais athéa!"}

(Mattoso: 2015, 159)

O gozo nada tem a ver com o prazer. E ele é sempre sinônimo de possíveis complicações: nada o explica e seu imperativo se opõe à felicidade, uma vez que em seu caminho há o sofrimento. Ele se deslinda do apolíneo e se volta para o dionisíaco, de que falava Nietzsche. É um perder-se. O gozo é interditado pelas leis da palavra, pelo nome do pai, mas sempre algo dele escapa. Sempre um algo dele aflora, passa pela estrutura significante, mas essa substância não será sexual. Para Lacan, a libido sexual está vinculada à castração e à falta.

O que se busca no corpo do outro, portanto, é o restinho de gozo que um objeto perdido nos propicie, falos que suplantem a nossa falta, ali onde um pornologos vaginal atue.

\section{Vaginal, o objeto a deambula}

Poesia vaginal é um livro de evidenciar que a mulher é toda falicizada, como dizia Lacan. É um canto à castração e suas perversões. Um objeto "a" que deambula pelos corpos, pois não é apenas de mulher que é feita a matéria vaginal desses poemas. No "Sonneto sadomita [1105]”, não apenas há o deslizar do vaginal da vagina para o ânus, como pelo trocadilho do título de Sade com sodomita. $\mathrm{O} 4^{\circ} \mathrm{e}$ o $12^{\circ}$ versos permitem uma leitura, que enfatizam uma voz poética homossexual masculina:

O coito anal é o symbolo mais vivo do sadomasochismo, pois, emquanto 
gargalha quem penetra, resta o pranto àquelle que assumiu papel passivo.

Na mesma proporção em que me privo do máximo prazer e me quebranto em dores, sei que um pênis eu levanto com meu gemido agônico e afflictivo

O macho que cavalga-me e me enraba questão não faz siquer de vaselina: eu mesmo o pau lhe unctei com minha baba!

Colloca-me de quatro, de menina me chama emquanto fode e, assim que acaba e esporra, ainda em minha boca urina!

(Mattoso: 2015, 39)

Se "Jogos frutais" dá título a um dos mais belos poemas de João Cabral de Melo Neto, é de outra natureza o jogo frutal que se faz nesse livro com o soneto "Propriamente desfructando [3958]", novamente um deslizar genital da genitália feminina para outro lugar, dessa vez para fora do corpo humano:

Já deu filme nacional

Essa história, mas me fala

Um amigo que é normal

O costume de estupral-a!

À mulher ninguém "faz mal":

Neste caso: o que se entalla 
É o caralho na fatal

Melancia... é só fural-a!

Si no cu leva a cenoura

Uma bicha, que lhe estoura

Todo o recto, por que não...?

Uma abobora ou moranga

Faz papel, quando balanga

Da mulher, tendo tesão!

(Mattoso: 2015, 151)

Vista assim, da leitura do vaginal o xibunguismo surge como uma de suas faces possíveis, não menos perversa que a mais estrita heterossexualidade.

Na contrafolha de rosto de Raymundo Curupyra, há uma informação importante sobre a opção ortográfica do poeta. Diz em nota que o livro não está conforme o acordo ortográfico Brasil-Portugal vigente desde $1^{\circ}$ de janeiro de 2009. E sim opta por uma ortografia etimológica havida desde a época clássica até 1940. Mas, se isso pode servir como explicação, há algo mais ali.

A ortografia em Glauco Mattoso é também uma marca transgressiva da norma, da regulação da lei (pois os acordos ortográficos no Brasil são matéria de lei), um prazer estético de buscar a forma apreciável e destacada da escrita. O significante que não se basta, nem morre no significado. Objeto vaginal. Mais interessante ainda porque é uma transgressão de um cego para o deleite de quem vê, desejo direcionado ao desejo do outro. 
Se pode se aproximar a perversão ao mal, e é assim que a sociedade costuma encarar aquilo a que ela denomina de perverso, como o mal, deve-se observar o que Freud aponta como o mal para o Eu no interior da sociedade, em O mal-estar na civilização:

Com frequência o mal não é, em absoluto, uma coisa nociva ou perigosa para o Eu, mas, pelo contrário, algo que ele deseja e lhe dá prazer. Aí se mostra, então, a influência alheia; ela determina o que será tido por bom ou mau. [...] Inicialmente o mal é aquilo devido ao qual alguém é ameaçado com a perda do amor $(2015,70)$. 


\section{Referências}

BIRMAN, Joel. Mal-estar na atualidade. Rio de Janeiro: Civilização Brasileira, 2014.

DELEUZE, Gilles. Sade, Masoch. Lisboa: Assírio e Alvim, 1973.

FREUD, Sigmund. O mal-estar na civilização. Tradução de Paulo César de Souza. São Paulo: Penguin; Companhia das Letras, 2015. LAPLANCHE, Jean \& PONTALIS, Jean-Bertrand. Vocabulário da psicanálise. Tradução de Pedro Tamen. São Paulo: Martins Fontes, 1992.

MATTOSO, Glauco. Poesia vaginal. São Paulo: Hedra, 2015.

. Raymundo Curupyra, o caypora. São Paulo: Tordesilhas, 2012.

MILLER, Gérard (org.). Lacan. Tradução de Luiz Forbes. Rio de Janeiro: Zahar, 1989.

RABINOVICH, Diana S. Sexualidad y Significante. Buenos Aires: Manantial, 1996.

RABINOVITCH, Solal. A foraclusão. Tradução de Lucy Magalhães. Rio de Janeiro: Zahar, 2001.

SALLUM, Jorge. "A grande sacanagem histórica de ainda escrever sonetos". In: MATTOSO, Glauco. Poesia vaginal. São Paulo: Hedra, 2015.

\section{Sites:}

www.academia.edu/13638898/Entrevista com Glauco Mattoso, acesso em 30/07/2018.

https://pt.wikipedia.org/wiki/Glauco_Mattoso, acesso em 12/04/2019.

www.enciclopedia.itaucultural.org.br/pessoa4836/glauco-mattoso, acesso em 12/04/2019. 


\section{Resumo}

Um poeta que se autointitula podólatra e praticante de uma estética xibunguista, um poeta famoso por seus aspectos transgressivos, pornográficos, lança um livro de cem sonetos sobre o ícone maior da sexualidade heterossexual e genital. Há uma contradição nesse novo livro em relação à obra anterior do poeta? Uma traição de suas propostas de cantor de sexualidades desviantes? Pelo sim, pelo não, como pensar esse livro? Pornográfico? Este trabalho busca empreender uma pequena compreensão do livro Poesia vaginal, de Glauco Mattoso. O que uma leitura psicanalítica pode dizer sobre esse conjunto de poemas? Poesia vaginal é um livro de poemas que aponta para questões constitutivas da sexualidade humana, como a formulação de Lacan de que "a relação sexual não existe" e as angústias dessa incompletude humana. Vê-se que o termo vaginal trata de algo muito mais amplo que o termo vagina, em última instância, de todas as faltas da sexualidade humana.

\section{Palavras-chave: Poesia vaginal; poesia brasileira; Glauco Mattoso; poesia e psicanálise.}

\section{Abstract}

A poet who calls himself a podiatrist and a practitioner of a xibunguista aesthetic, a poet famous for its transgressive, pornographic aspects, launches a book of one hundred sonnets for the greatest icon of heterosexual and genital sexuality. Is there a contradiction in this new book in relation to the poet's earlier work? A betrayal of his proposals as a singer of deviant sexualities? But to be on the safe side, what to think about this book? Is it pornographic? This work aims to undertake a comprehension of the book Poesia vaginal, by Glauco Mattoso. What a psychoanalytic reading can say about this set of poems? Poesia vaginal is a book of poems that points to constitutive issues of human sexuality, such as Lacan's formulation that "sexual intercourse does not exist" and the anguish of this human incompleteness. It is seen that the term vaginal 
deals with something much wider than the term vagina, and ultimately all the faults of human sexuality.

Keywords: Vaginal poetry; Brazilian Poetry; Glauco Mattoso; poetry and psychoanalysis. 